\title{
Recent aspects in simulated moving bed
}

\author{
J. Blehaut and R.-M. Nicoud
}

NOVASEP, BP. 50, 54502 Vandoeuvre-lès-Nancy Cedex, France

Simulated moving bed (SMB) is a continuous, counter-current binary separation technique, more and more used in the separation of fine chemicals and pharmaceuticals. The first industrial SMB units have now been implemented in the pharmaceutical industry, for the separation of optical isomers.

This article describes some of the most important features which now belong to SMB dedicated to applications in the fine chemistry:

- The separation of optical isomers, a very critical technical problem for the pharmaceutical industry is now well solved at large scale thanks to the SMB technique. SMB is often not used alone, but when possible in coupling with enantioselective crystallization (the SMB is used to pre-purify a crude material with a high robustness and an enhanced productivity, while crystallization is used to "polish" the enantiomer).

- Very short columns (less than $10 \mathrm{~cm}$ long) have been optimized to take advantage of very small stationary phase particles now used in chromatography. For chiral separations, they allow to dramatically decrease the overall separation process cost.

- Softwares play a much more important role than before: simulation tools allow to numerically optimize the SMB parameters for nearly all kinds of molecules with a very limited number of experiments and to help validate the separation process with simulated "worst cases", while improved control softwares allow to circumvent some technical difficulties due to the asymmetry of SMB systems.

- The way to consider the SMB and the associated evaporation unit in a single unit operation lead to a well-defined process which may reduce the number of in-process controls and the consequences of non conformity of the product.

Beside liquid SMB, this article introduces a more recently developed SMB process, working with supercritical eluent. This technique might find interesting applications especially in the separation of certain lipidic compounds.

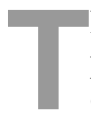
he Simulated Moving Bed (SMB) technology has been patented about 40 years ago [6]. It is a multi-column, continuous chromatographic binary separator, involving a counter-current between the liquid (eluent) and the separating medium (stationary phase) packed in the columns.

The SMB found very important applications mainly in the petro-chemical industry (separation of p-xylene from its isomers on zeolithes) and in the sugar industry (separation of glucose and fructose on styrene-divinylbenzene resins). More than 100 industrial plants have been built to date for such applications, and this technology still has a big success: the biggest plant in the world (Eluxyl technology, designed by the IFP, France) has been erected in South Korea. It is composed of columns of more than 7.0-meter i.d. [21]! For these applications, numerous (12 to 24$)$ very long ( 1 to 2 meter) columns are implemented, since the stationary phases used are coarse $(200 \mu \mathrm{m}$ to several $\mathrm{mm}$ particle size $)$ and hence have low efficiencies. The development of such processes has been made possible because of relatively simple chromatographic behaviour (linear adsorption or large selectivities) and because of a significant time allocated to the develoment.

In the 70's, High Performance Liquid Chromatography (HPLC) was developed for the preparative separation of fine chemicals, involving much smaller stationary phase particles (usually 10 to $40 \mu \mathrm{m}$ ). Consequently, shorter (usually 20 to $50 \mathrm{~cm}$ long) columns are operated, under high pressure (up to 100 bar). This technique is known to be very efficient but expensive because of an important dilution of the products and limited specific productivity.

Since the 80 's, constraints regarding product purities edicted by pharmaceutical and food regulatory organisations (lead by the american FDA) drastically increased and are the cause of an increasing demand of technologies allowing to obtain quickly pure products (especially enantiomers).

Moreover, the recent and tremendous development of biotechnologies results in the production of more and more new active compounds (enzymes, peptides, antibiotics), often being produced by fermentation, requiring complex purification steps to yield the desired molecule.

The integration of High Performance Liquid Chromatography in the SMB (HP-SMB) concept has led to 
a process which is both versatile and economical. This process seems to answer properly to a demand: a number of separations of molecules having an industrial interest have been achieved to date at the lab or pilot scaleand first industrial HP-SMB units are now used by pharmaceutical companies for the enantioseparation of active compounds.

After nearly ten years of SMB development in the fine chemicals field, this article presents the state of the art and the most recent trends linked to the development of the High Performance SMB technology.

\section{Principle - theoretical aspects}

The principle of the technique has been described in numerous publications [42]. The reference process is the true moving bed (TMB) where a counter-current between a solid and a liquid is achieved in a single column, as described in the figure 1. A binary mixture to be separated (or feed) is injected at the middle of the column. Both the solid and the liquid (or eluent) are chosen, so that the compounds present in the feed are not adsorbed equally on the solid. Four zones clearly appear in the TMB column, in order to allow an actual separation of both compounds:

- In the zone I, between the injection of the eluent and the collection of the extract, the more retained compound has to be desorbed from the solid, i.e. to move upwards;

- In the zone II, between the collection of the extract and the injection of the feed, the less retained compound has to be desorbed from the solid, i.e. to move upwards;

- In the zone III, between the injection of the feed and the collection of the raffinate, the more retained compound has to be adsorbed on the solid, i.e. to move downwards;

- In the zone IV, between the collection of the raffinate and the injection of the eluent, the less retained compound has to be adsorbed on the solid, i.e. to move downwards.

These four conditions can be simultaneously achieved, provided that the operating parameters (four independant liquid flow rates and the solid flowrate) are adequately chosen.

On a technical point of view, the TMB concept cannot be implemented, as the circulation of a solid in a column creates numerous problems (attrition, lack of efficiency, liquid velocity limited by the fluidization...). Consequently, the only way to implement the moving bed concept is to discretize the counter-current column in identical fixed bed columns connected in series, achieve a liquid circulation in the columns, and periodically switch the injection and withdrawal points from one column to the following one, so that it simulates the movement of the solid (as described in the Fig. 2).

In the SMB implementation, the solid is not moving anymore like in the TMB, the counter-current effect being associated to the shift of the inlet/outlet lines. The solid flowrate of the TMB is linked to the shift period, the column volume and porosity by:

$$
\bar{M}=(1-\varepsilon) \cdot V_{\mathrm{col}} / \Delta T
$$

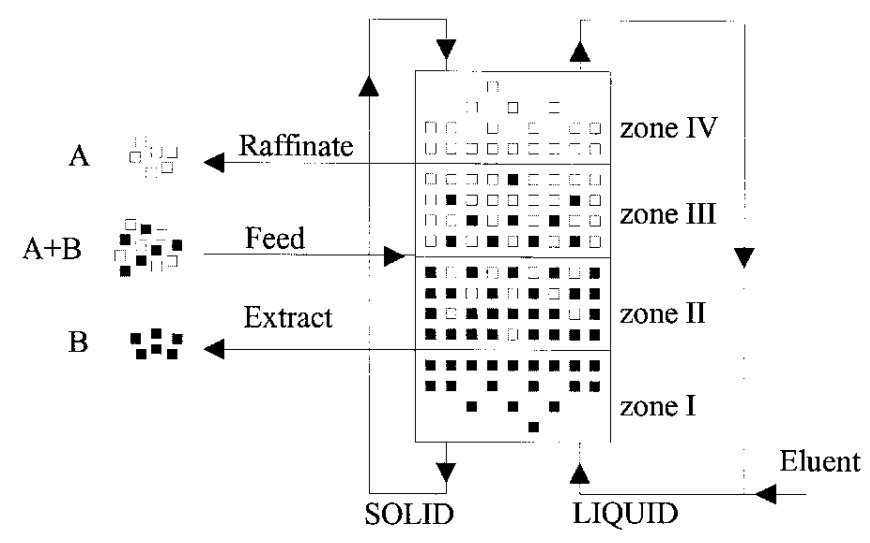

Figure 1. Principle of the TMB.

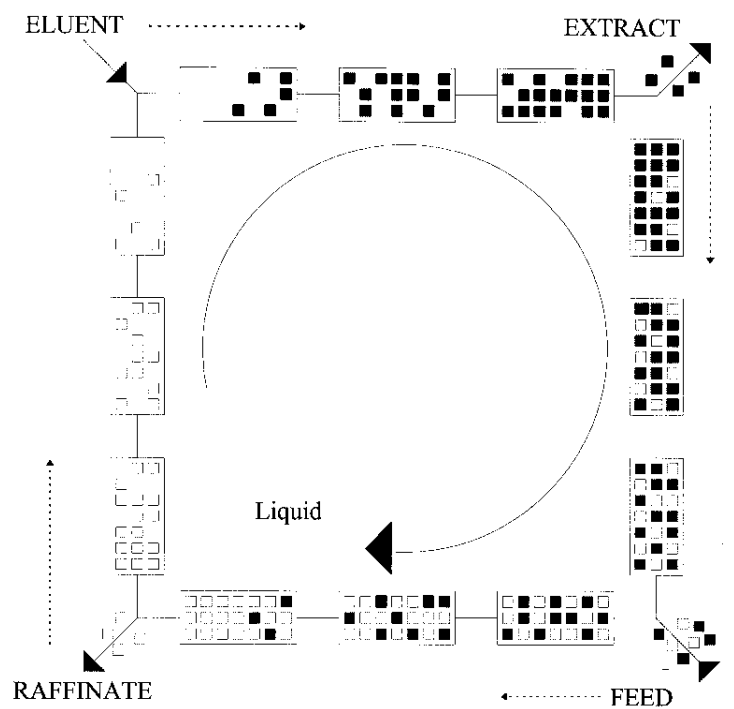

Figure 2. Principle of the SMB.

The experience shows that SMB and the hypothetical TMB have very close performances, provided that the SMB is made of 8 to 12 columns.

Both processes are counter-current processes, allowing an increased performance, compared to classical chromatographic processes:

- the requirement of chromatographic efficiency (number of theoretical plates) is lower,

- the specific productivity is usually higher,

- the dilution of the products is lower.

It is out of the scope of this article to give a precise comparison between the counter-current and batch processes, however, one can state that the interest of SMB is maximized when the selectivity is small and the packing not very efficient (not many plates per meter). It has also been shown that the SMB is more stable than batch chromatography.

Systems of different sizes are now available as shown in figure 3 . 
Finally, it must be stated that the users can now simply purchase some SMB plants from different suppliers. Beside NOVASEP (Vandoeuvre les Nancy, France; Gibbstown, NJ, USA), companies like PROCHROM (Champigneulles, France), UOP (Des Plaines, IL, USA), (KNAUER, Berlin Germany) and MITSUBISHI (Japan) also offer some plants of different sizes.

\section{Applications}

During the last decade, the SMB process has been used and adapted for very different applications. In the following we have arbitrarily decided to classify the main applications in bioseparations, separation of organic molecules and optical isomers.

\section{Bioseparations}

There are many bioseparation problems for which SMB can be used. Most of them are presented in the following.

Separation of sugars: This application is the most known, and the separation between fructose and glucose is one of the largest application of chromatography. Since the pioneering work of Barker [3], this separation has been investigated by many workers $[9,10,25]$. A review of the work done by the Barker's team is given in [17]. This separation is performed on ion exchange resins, using warm water as eluent. The preferred implementation consists in using polystyrene cation exchange resins in the calcium form: fructose forms a complex with the calcium ions and is retarded, glucose and other oligosaccharides are eluted with the eluent. In order to improve the productivity, some work has been done with zeolites (calcium form) instead of resins [24]. Another possibility consists in using anion exchange resins in the bisulfite form, glucose being retarded by complexing with the bisulfite, the other oligosaccharides being eluted first. This option is not used at production scale because of the lower stability of anion exchange resins.
The Sarex process has been reported [5] to be used to separate continuously a $500 \mathrm{~g} / \mathrm{L}$ inverted carbohydrate syrup containing $42 \%$ fructose giving 90 to $94 \%$ pure fructose at recovery of over $90 \%$. The glucose rich fraction is about $80 \%$ and both product concentrations were about $200 \mathrm{~g} / \mathrm{L}$. This separation can be implemented on columns of a few meters internal diameter.

SMB packed with cationic resins in the calcium form have also been used for obtaining other monosaccharides like xylose or arabinose [1]. Experiments have been performed using a feed mixture containing $21 \mathrm{~g} / \mathrm{L}$ of glucose, $155 \mathrm{~g} / \mathrm{L}$ of xylose and $20 \mathrm{~g} / \mathrm{L}$ of arabinose, the retention order being glucose then xylose then arabinose. The goal was to obtain a raffinate with no detectable traces of arabinose with a maximum recovery of xylose. The goal was reached as the following extract and raffinate composition were obtained:

raffinate: glucose: $8.26 \mathrm{~g} / \mathrm{L}$; xylose:73.69 g/L; arabinose: below detection limit

raffinate: glucose: $0.09 \mathrm{~g} / \mathrm{L}$; xylose:0.47 g/L; arabinose: $14.16 \mathrm{~g} / \mathrm{L}$.

This application examplifies perfectly that SMB is a binary separator: it allows to split a mixtxure in two fractions even if this mixture contains more than 2 products.

Another interesting application is devoted to the separation between mono and disaccharides or between disaccharides. For instance [31] studied the separation between palatinose and trehalulose and results obtained by NOVASEP for the separation between fructose and trehalulose are available (to be published in the chapter "SMB: some possible applications for biotechnology" of the book entitled "Bioseparation and Bioprocessing" edited by G. Subramanian published by $\mathrm{VCH}$ ).

The SMB technology has also been used for performing the fractionation of dextran (polyglucoside mainly used as a blood plasma volume expender) by size exclusion [17]. The columns were packed with Spherosil XOB075 of 200 to
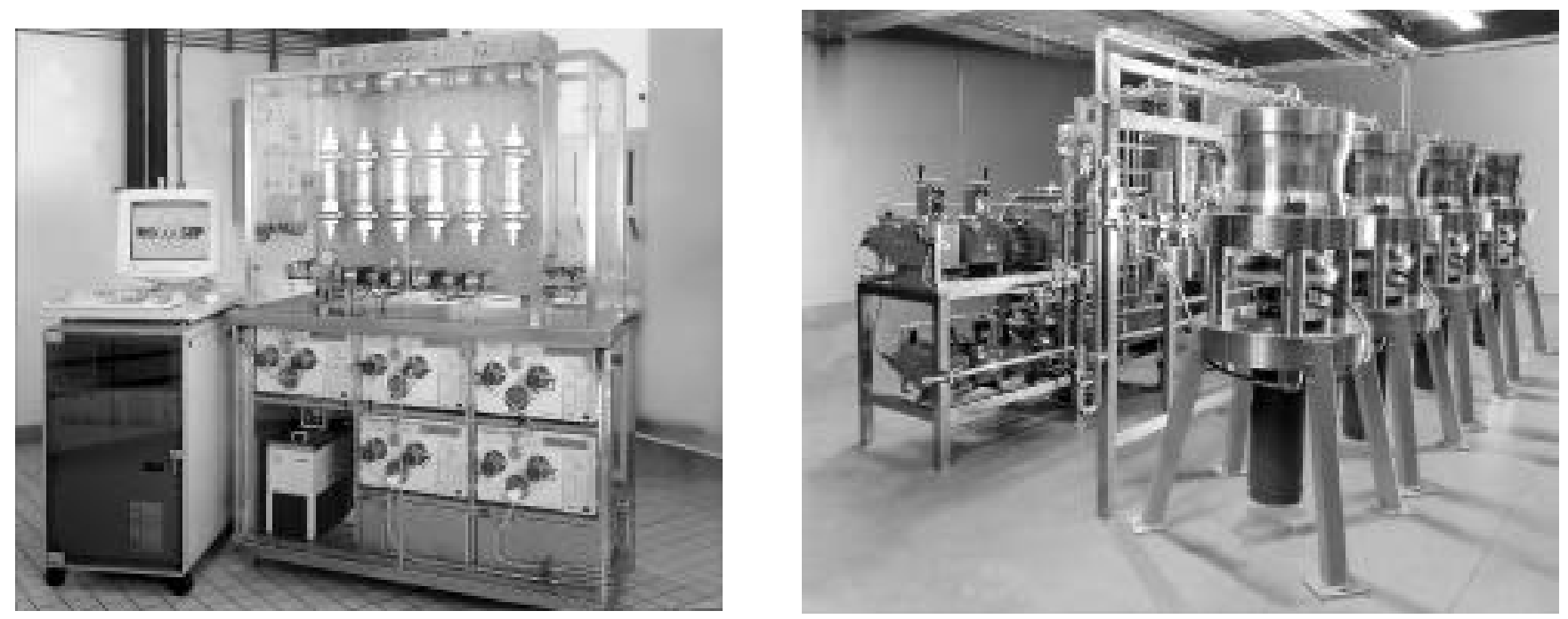

Figure 3. Some photos of HP-SMB systems. Left: Licosep-Lab (Laboratory scale SMB made of 12 columns of 2 to $5 \mathrm{~cm}$ i.d.) Right: Licosep 6-450 (Production scale SMB made 6 columns of $45 \mathrm{~cm}$ i.d.). 
$400 \mu \mathrm{m}$ porous silica beads, and the technology has allowed to obtain, according to the flowrates, very different fractions (from 10000 Dalton to 125000 Daltons).

Desalting: Desalting is a second simple and interesting application of SMB in biotechnologies. Different mechanisms can be used like ion-exclusion, hydrophobic interaction, size exclusion or ion retardant effect [24].

Glucose and $\mathrm{NaCl}$ have been separated on Retardion 11 A-8 [33], very high purity products have been reported for feed mixtures containing $3 \mathrm{~mol} / \mathrm{L}$ of glucose and $3 \mathrm{~mol} / \mathrm{L}$ of $\mathrm{NaCl}$. In that case, the adsorption isotherms are favorable (Langmuirian type).

A similar work has been performed in order to separate $\mathrm{NaCl}$ from Glycerol on Amberlite HFS-471X (8\% DVB) which is a strongly acid cation exchange resin in the sodium form. In that case, the mechanism is ion exclusion (the glycerol can enter the internal porosity of the resin when the salts are excluded). The adsorption isotherm of glycerol is linear (as expected because glycerol has no interaction with the resin: it just enters in the internal porosity) while the adsorption isotherm of the salt is non favourable (anti-langmuir) as expected from an ion exclusion process (Donnan behavior).

Instead of ion-exclusion, the size exclusion process has been used for performing the separation between $\mathrm{NH}_{4} \mathrm{SO}_{4}$ and a protein [24]. In that case, the adsorption isotherms were simply linear.

Finally, an hydrophobic interaction has been used by Hashimoto [26] for performing the separation between phenylalanine and $\mathrm{NaCl}$. In that case, $\mathrm{NaCl}$ having almost no interaction with the packing had a linear adsorption isotherm, when the phenylalanine exhibited a classical Langmuirian adsorption isotherm.

Purification of proteins: Only a few references regarding the use of SMB for performing the separation between proteins have been reported.

The first attempt can be probably credited to Huang et al. [28] who performed the purification of trypsin from extract of porcine pancreas. They used successfully a SMB made of only 6 affinity columns which shows that SMB can be attractive even with a very limited number of columns. Although the 4-zone process had fairly high performances in separation efficiency, the addition of a fifth zone used as a washing section was advised.

A recent proposal consists in performing the purification of Human Serum AlbuminHSA [27] on two SMB connected in serie: the first one being used for removing the less strongly retained components, the second one for removing the more strongly retained components.

Finally, some results concerning the separation between Myoglobine and Lysosyme have been presented recently [43]. This separation can be performed on a support like ACA 54 (Biosepra, France) with an eluent containing $\mathrm{NaCl}$ $0.15 \mathrm{M}$ in water [19]. On a SMB made of 8 columns of $2.6 \mathrm{~cm}$ i.d. and $0.1 \mathrm{~m}$ length, very pure extract $(>98 \%)$ and raffinate $(>98 \%)$ can be obtained from a $50-50$ mixture at $2 \mathrm{~g} / \mathrm{L}$.
Finally, SMB has also been applied for the purification of monoclonal antibodies [18], the technique leading to excellent purities and yield.

Separation of ionic molecules: The SMB technology has also been used for performing the purification of different ionic molecules.

For instance, large scale production of lysine can be performed by SMB [54]:

Pure betaine can be obtained from molasses via a process involving two chromatographic steps [29]:

step 1: a fraction containing a mixture betaine+glycerol is separated from the rest of the feed (mineral, carboxylic acids) thanks to ion exclusion,

step 2: glycerol is separated from betaine in a second ion exclusion step.

L-glutathione [34] produced by yeast fermentation is a tripetptide used in cases of liver diseases. High purity L-glutathione (99\%) is required in the final crystallisation step. The obtention of this highly pure glutathione is difficult especially because of the presence of amino-acids, one of the limiting species being glutamic acid. The separation between the L-glutathione and glutamic acid is performed on a cation-exchange resin (Rohm \& Haas, Amberlite IR200C, $350-590 \mathrm{~mm}$ ). The separation has been implemented in a SMB made of 16 columns of $1 \mathrm{~cm}$ i.d. and $10 \mathrm{~cm}$ or $20 \mathrm{~cm}$ length. The SMB parameters have been determined via a procedure which is similar in essence to the procedure given in section 3 (determination of the internal flowrates thanks to the knowledge of the adsorption isotherms). Operating at $0.05 \mathrm{~mol} / \mathrm{L}$ of $\mathrm{HCl}$ (the $\mathrm{pH}$ value controlling obviously the adsorption of both products on the resin) the glutathione was obtained in the raffinate stream at $1.62 \times 10^{-3} \mathrm{~mol} / \mathrm{L}$ at $99 \%$ purity with $99 \%$ yield. The productivity was $4.52 \times 10^{-4} \mathrm{~mol} / \mathrm{L}$ of adsorbent $/ \mathrm{min}$

\section{Separation of organic molecules}

A lot of separations of organic molecules for fine chemistry have been performed with the SMB technology, but according to our knowledge, only a few of them have been published.

Some work has been done in order to perform the separation of fatty acids. The first results have been published by Szepy [52] and were associated to the separation of $\mathrm{C}_{16}$ to $\mathrm{C}_{22}$ methyl esters. An interesting patent has been granted to PRONOVA (1996) which associates classical (batch) chromatography with an SMB with two inlets for obtaining pure $\operatorname{EPA}(\mathrm{C} 20)$ and pure $\operatorname{DHA}(\mathrm{C} 22)$ from fish oil: this nicely examplifies the need to associate different technologies in order to optimize a production process.

Recently, the separation of the stereoisomers of phytol (3,7,1,15-tetramethyl-2-hexadecen-1-ol, $\left.\mathrm{C}_{20} \mathrm{H}_{40} \mathrm{O}\right)$ has been described [4] at a relatively large scale (about $20 \mathrm{~kg} /$ day). The synthetic phytol is a mixture of cis (33\%) and trans $(67 \%)$ isomers, the latter being used in perfumery. The separation between the phytol isomers is performed on classical silica (Lichroprep Si 60, 25 - $40 \mu \mathrm{m}$ from Merck KGaA, Darmstadt) with an eluent made of heptane - ethyl acetate $(75 / 25 \mathrm{v} / \mathrm{v})$ at $27{ }^{\circ} \mathrm{C}$. This separation is implemented on a Licosep 8-200 (NOVASEP) which includes 8 axial 
compression columns of $200 \mathrm{~mm}$ i.d. and up to $400 \mathrm{~mm}$ long. For this particular case, columns were packed with 3 $\mathrm{kg}$ of silica leading to a column length of $17.7 \mathrm{~cm}$.

\section{Separation of optical isomers}

The two first references disclosing the use of SMB for performing optical isomers separation were published in 1992 by Negawa on phenyl-ethyl alcohol [38] and Fuchs on threonine [16].

The first anouncement of the development of a real industrial example has been made by Sandoz (Chemical Engineering, November 1992): this separation described by Nicoud et al. [44] is briefly presented below. The enantiopurification of the ( \pm )-1a,2,7,7a-tetrahydro-3-methoxynapht(2,3-b)-oxirane (SANDOZ Pharma) is important because this epoxyde is a valuable intermediate in enantioselective synthesis. The separation was performed using microcrystalline cellulose triacetate (C.T.A.) from MERCK KGaA (Darmstadt, Germany) as stationary phase and pure methanol as eluent. The frontal analysis and isotherms determination were carried out on Superformance columns (MERCK, DARMSTADT) of $2.6 \mathrm{~cm}$ I.D. and $11 \mathrm{~cm}$ length, packed with $25-40 \mathrm{~mm}$ C.T.A.

After these very first first examples, a first wave of publications dealing with products of industrial interest were published:

Chiral hetrazepine [45], WEB 2170 6-(2-chlorophenyl)-89-dihydro-1-methyl-8-[(morpholinyl)-carbonyl]-4H, $7 \mathrm{H}$-cyclopenta[4,5]-thieno[3,2-f][1,2,4] triazolo[4,3a] $[1,4]$ diazepine from BOEHRINGER-INGELHEIM.

Enantioseparation of a chiral thiadiazin-2-one, EMD 53986 [46]. The separation of EMD 53986, 3,6-Dihydro-5[1,2,3,4-tetrahydro-6-quinolyl]-6-methyl-2H-1,3,4-thiadiazin-2-one, a precursor in the synthesis of a promizing calcium sensitizing agent from MERCK KGaA.

Enantioseparation of the enantiomers of praziquantel [11]: the separation of the enantiomers of this antihemintic drug was carried out on a 4-column SMB made of columns of $12.5 \mathrm{~mm}$ I.D. and packed with cellulode triacetate and methanol as eluent.

Separation of the enantiomers of $\beta$-Blockers (Ikeda, 1993).

After this pioneering works, some users (researcher in pharmaceutical companies) started to disclose how they use and how they consider the SMB in their own laboratories [7,15,20,32,37].

The first demonstration of large scale separations of optical isomers with SMB was performed by SEPAREX Chromatographie (former team of NOVASEP) in 1994, on the LICOSEP 8-200 [published in the summary report of the BRITE-EURAM project BRE2-CT92-0337], which led to the separation of $2 \mathrm{~kg}$ of racemic binaphthol per day on a Pirkle type 3,5-DNBPG-Silica CSP (MERCK KGaA, Germany). Just like for the first examples presented at the laboratory scale, this binapthol example is very far to be the most productive, and it is mainly given here for its historical interest.

The interest of SMB for performing large scale separations of optical isomers is now recognized (very short devel- opment time, extremely high probability of success, attractive purification cost...), and a lot of industrial developments are performed. However, because of strong confidentiality constraints, information available to the public is very limited, and major anouncements are summarized below.

DAICEL anouncement: Daicel has anounced an investment in a SMB production plant (LICOSEP 12-100) installed in their facilities at Arai (Japan). This plant allowing productions from $\mathrm{kg}$ up to hundreds of $\mathrm{kg}$ per year is now under utilisation, and a drug is currently purified for Nissan Chemicals (Japan Chemical week, 4 december, 1997).

UCB anouncement: UCB Pharma (Belgium) has anounced (May 15, 1997 in a meeting organized in Nancy) its decision to install a SMB made of columns of $450 \mathrm{~mm}$ i.d. (LICOSEP 6-450) in order to perform multi-tons separation of the enantiomers of a drug.

Very similar approaches are currently taken by several other pharmaceutical companies, and other anouncements of the use of SMB for performing large scale enantioseparations are expected in a near future.

\section{The High Performance SMB (HP-SMB)}

The evolution of the industrial needs has led to a very strong evolution of the SMB technology (and thus to the birth of High-Performance SMB) because of the needs to save time in the development steps (and to develop very quickly new applications), to optimize the needs in expensive packings, to handle the GMP constraints.

\section{Modelling}

One of the most noticeable evolution led by the success of SMB is the recent acceptation by the pharmaceutical industry of modelling as a practical tool for quick and efficient process optimization [20,37]. This evolution has been initiated by SMB suppliers (because of the need to rationally develop this complex process), the first modeling software allowing the optimization of non linear separations by SMB being presented in the early 90's. This evolution is now amplified thanks to the more and more numerous contributions of universities to a better understanding of the system [35,36,49,51].

The principle of modelling and of the way to optimize the productivity of a SMB separation has been extensively described elsewhere [8] and is briefly summarized here:

\section{Step A: Acquisition of relevant physico-chemical parameters}

In order to rigorously calculate the process, only a few relevant parameters are to be experimentally determined on a laboratory scale column: equilibrium adsorption isotherms, column efficiency (number of theoretical plates), estimation of the pressure drop.

We want to stress on the fact that these determinations are absolutely not as tedious as sometimes claimed, and 
nowadays some computer softwares are available allowing a very simple work.

\section{Step B: Calculation of the TMB}

For given feed composition, eluent, and stationary phase, the flowrates of a TMB allowing to process a given flowrate of feed are calculated on the basis of the knowledge of the adsorption isotherms.

Optimum flowrates, i.e. giving the highest productivity and the lowest eluent consumption, are estimated first for an "ideal system" what mainly means that kinetic and hydrodynamic dispersive effects are assumed to be negligible. This procedure is sensible because it has been proven that TMB or SMB performances are only slightly sensitive to the number of plates [53].

\section{Step C: Calculation of the SMB}

Using SMB flowrates simply derived from those of the TMB, the SMB behavior is simulated according to the number of columns and equivalent number of plates per column.

The number of columns and equivalent number of plates per column are determined in order to get the expected purities and yield.

At this level, the flowrates, the number of columns and required plate number are known. The column diameter and length are calculated by taking into account the constraints given by the Van Deemter and the Darcy's laws.

A number of preparative separations on SMB systems optimized thanks to a simulation software have been published to date, and as an example, NOVASEP has optimized and achieved more than 50 separations since 1990, most of them being kept confidential for industrial reasons.

\section{Columns: The "camembert" concept}

The recent evolution of the SMB technique has of course been strongly influenced by economic criteria, such as the price of stationary phase, which is a big part of the cost breakdown of an industrial separation. For chiral separations on SMB, it has been shown that the chiral stationary phase (CSP) can represent more than $50 \%$ of the overall production cost, in the 10 to 100 tons/year production range (Nicoud, 1996). Figure 4 shows that the cost optimization of a separation is completely different whether resins or non grafted silica are involved or if chemically modified silicas (such as RP18 silica or most of the chiral stationary phases) are used.

In the former case, the cost of the stationary phase decreases as particle size increases: the chemistry is simple, and most of the cost is related to particle sieving. Therefore, the most cost effective system may involve coarse stationary phase (in the $100 \mu \mathrm{m}$ range or above) in long columns: the stationary phase cost is minimized, as well as the investment cost (especially linked to the columns), since the operating pressure will be lower in such systems.

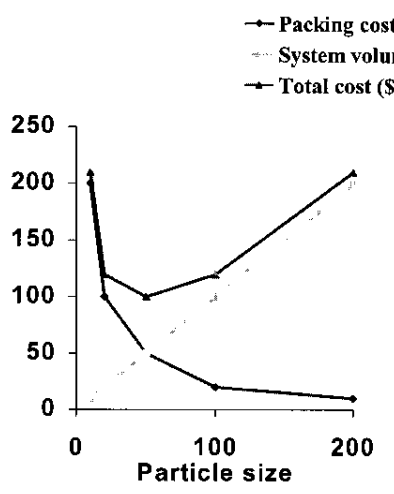

Resins, silica

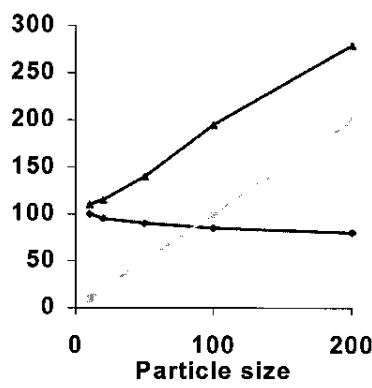

Chemically modified silica Optically active packings
Figure 4. Schematic influence of the particle size on the cost of the adsorbent inventory.

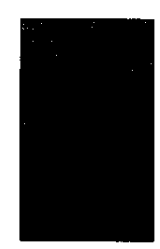

5 bars

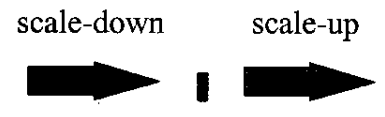

60 bars

1990
60 bars

1997
Figure 5. Evolution of the SMB technology.

In the latter case, the cost of chemically modified silica is essentially linked to the chemical modification itself (use of expensive monomers and coupling agents or polymers). The cost of the stationary phase will be nearly proportional to its total volume. Therefore, the smaller the stationary phase volume, the cheaper the process. Consequently, the optimal system will be packed with small stationary phase particles, having the highest efficiency and specific productivity ( $\mathrm{kg}$ of product purified/kg of stationary phase/day).

As small particle sizes (having high intrinsic efficiencies) have to be used for the above mentioned reasons, the SMB optimization - especially for chiral separations - leads to very short columns: usually between 5 and $10 \mathrm{~cm}$ for 15 to $25 \mu \mathrm{m}$ stationary phase particle sizes. Figure 5 summarizes the evolution of SMB column technology since 40 years.

The first scale-down showed that lab-scale SMB having short columns packed with small particles and operated between 50 and 100 bars are the most efficient. As small particle size stationary phases can now be produced in bulk quantities, the scale-up simply results in increasing the column diameter (and keeping liquid velocities, concentrations and switching times constant). The column diameters of SMB industrial systems already built range between 10 and $45 \mathrm{~cm}$, leading to multi-ton/year production of pure products (such as enantiomers). Before the third millenium 
turn, SMB systems having 1 meter i.d. columns should be operated for chiral separations at the 100-ton/year scale. Therefore, one can speak of "camembert" type columns. One of the key points of the scale-up is linked to the ability of the SMB suppliers to optimize the flow distribution in short, large columns. Efficient tools for hydrodynamic modeling are already mastered.

\section{“Asymmetric” SMB?}

The most widely used way to implement the SMB concept is described in figure 6. The system is mainly composed of the following elements:

- one pump for each inlet and outlet flow, featuring feed, eluent, raffinate and extract. Both outlet flows can also be controlled by analog valves.

- one recycling pump, located between the last and the first columns

- a series of two-way valves, allowing to connect each inlet and outlet line to each column.

The use of an internal recycling pump allows to keep almost constant the hydrodynamic pressure in each column, avoiding strong and cyclic pressure changes in the columns occuring with the other possible SMB implementations. This feature has proven its efficiency and robustness in nearly all industrial SMB plants.

An essential condition for the SMB to be effective is the following: retention times of the solutes must be as close as possible from each other in all columns. Practically, this condition is very easy to fulfill, since the amount of stationary phase in each column can be precisely weighed, and the packing conditions are very reproducible. However, as one can easily see in figure 6 , the presence of the recycling pump induces an asymmetry in the SMB, since the dead volume associated to it might not be negligible. This is particularly true when small particle sizes are used: the columns being short their volume is very small, and the influence of the dead volume is significant.

The effect of this asymmetry has been measured experimentally on a lab-scale system in the case of stereoisomers separation, with the following experimental conditions.

System: LICOSEP 12-26 (NOVASEP, France); columns: 12 of $2.6 \mathrm{~cm}$ i.d. and $10.5 \mathrm{~cm}$ length;

Eluent: heptane / ethylacetate $(75 / 25 \mathrm{v} / \mathrm{v})$; feed: cis-trans phytol (22/67 \%/\% mixture), $50 \mathrm{~g} / \mathrm{L}$ in the eluent;

Stationary phase: Si 60 Angström, 15 - $25 \mu \mathrm{m}$ (ALLTECH, France); amount of silica in each column: $20 \mathrm{~g}$;

Temperature: $25^{\circ} \mathrm{C}$; recycling dead volume: $20 \mathrm{~mL}$;

flowrates:

Recycle: $49.2 \mathrm{~mL} / \mathrm{min}$; feed: $1.6 \mathrm{~mL} / \mathrm{min}$; eluent: $6.8 \mathrm{~mL} / \mathrm{min}$; extract: $6.8 \mathrm{~mL} / \mathrm{min}$; raffinate: $1.7 \mathrm{~mL} / \mathrm{min}$ period: $1.5 \mathrm{~min}$.

Figure 7 shows the average purity of both outlet streams being collected at successive periods of a complete SMB cycle. The purity of both extract and raffinate streams is poor (about 90\%).

Two ways of circumventing this asymmetry have been patented to date:

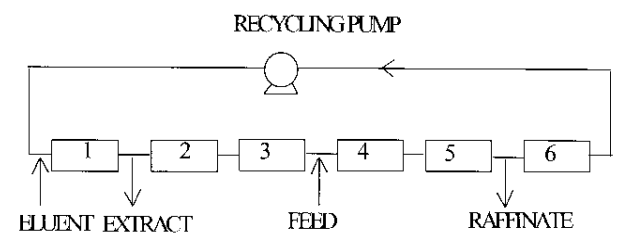

Figure 6. Schematic flowsheet of a SMB.
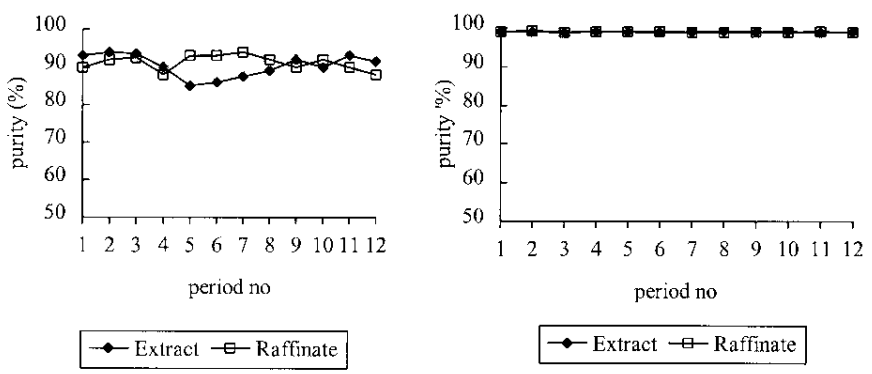

Figure 7. Influence of a dead volume located at the recycle pump level on the performances of a SMB (phytol isomers). Experimental conditions given in the text. Left: without compensation; right: asymetric shift.

- The last or the first column are shorter, so that the average residence time of the compounds in the shorter column plus the recycling dead volume is equal to the average residence time in the other columns. In the later case, all valves are switched simultaneously [23].

- Valves aren't switched simultaneously anymore, but the one being just before the recycling pump is automatically switched with a delay, equivalent to the time needed for the liquid to pass through the recycling dead volume [22].

The purity profiles shown in figure 7 have been obtained in the same conditions as the ones shown in figure 7, except that valves are switched non simulaneously. Both stereomers have been simultaneously purified at more than $99 \%$.

\section{SMB as a piece of a complete puzzle}

Even if a very important part of the separation process (the heart?), SMB must considered as a simple piece of a more complex system.

\section{Evaporation}

As any industrial chromatographic process, the SMB has to be coupled to a solvent recycling unit (Fig. 8), allowing to recycle pure eluent and to concentrate the product streams.

There are two ways to consider the eluent recycling process:

- a separate unit operation,

- as integrated in the separation unit. 


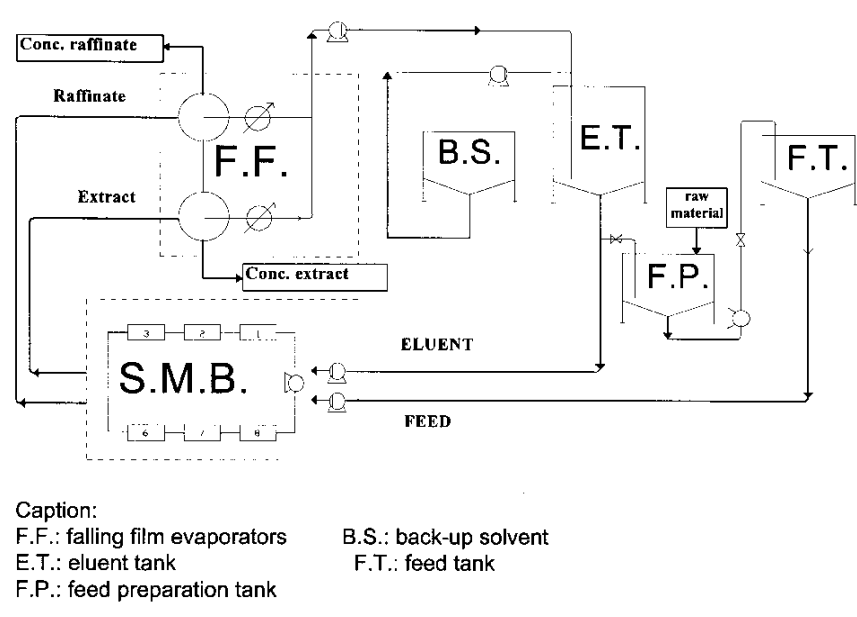

Figure 8. Schematic representation of a SMB included in a solvent recycling loop.

These two approaches lead to significantly different systems:

- if the first concept is considered, then dilute products withdrawn from the SMB have to be analysed batchwise, so that the quality of the products entering in the eluent recycling system is controlled for GMP reasons. Consequently, important storage capacities have to be considered, between the SMB and the evaporation unit. Similarly, the recycled solvent has also to be analysed before entering in the SMB system.

- if the eluent recycling is considered as part of a single unit operation (SMB leading to pure concentrated products), then only the concentrated products are the outlet of the unit operation and have to be analysed. Obviously, in-process analysis of the dilute extract and raffinate streams should be handled (as well as analysis of the eluent tank), so that any decrease of the SMB performances can be detected as soon as possible, and corrected while the products are still above the expected specifications.

The first industrial SMB systems operated in and for the pharmaceutical industry have been designed following the concept of integrated eluent recycling. On the economic point of view, it has to be underlined that important gains are obtained:

- by the reduction of the storage capacities (investment costs): available eluent composition analysis and adjustment systems lead to a single eluent tank between the evaporators and the SMB.

- by the diminution of the quantity of QC analysis (operating costs).

It also has to be noticed that smaller storage capacities allow to decrease the chemical and environmental risks (costs of overheads).

\section{Crystallisation}

Even if SMB is perfectly able to deliver enantiomers at very high purities, the association of a SMB delivering enriched fractions with another separation technique allowing to obtain the final purity may be investigated in order to maximize the global productivity.

All researchers involved in the development of chiral molecules know that one can take advantage of the enantioselective crystallization properties of already enriched enantiomeric mixtures. This has been extensively modeled by Professor A. Collet and his team [13]. For about $90 \%$ of the chiral compounds (called true racemates), the solubility of an enriched enantiomer in a given solvent reaches a maximum for a given enantiomeric excess (equivalent to the eutectic point of the solid-liquid diagram of the chiral mixture). This is due to the fact that two different species are found when the mixture is recrystallized: racemate crystals will appear first, until the enantiomeric composition of the liquid phase reaches the pseudo-eutectic point, then crystals of pseudo-eutectic will appear (if the enantiomeric excess is inferior to the one of the pseudo-eutectic point), or pure enantiomer crystals will appear (if the enantiomeric excess is superior to the one of the pseudo-eutectic point), followed by crystals of pseudo-eutectic.

Consequently, if the enantiomeric excess of the desired enantiomer produced by a SMB is superior to the one of the pseudo-eutectic point, the recrystallization will yield pure enantiomer.

This property is very interesting, since it allows to simultaneously reach two goals:

- remove the other optical isomer,

- remove chemical impurities, like any classical recrystallization.

The interest of coupling SMB and enantioselective crystallization has been experienced with the chiral ester LS 2904 separated under the following conditions:

System: LICOSEP 12-26 (NOVASEP, France); 12 columns of $2.6 \mathrm{~cm}$ i.d. $\times 9.2 \mathrm{~cm}$ length;

Eluent: heptane/2-propanol $(91.5 / 8.5 \mathrm{v} / \mathrm{v})$,

feed: racemic mixture, $3 \mathrm{~g} / \mathrm{L}$ in the eluent (close to the solubility limit);

Chiral stationary phase: Celluspher (cellulose trip(methyl)benzoate, 20 - $43 \mu \mathrm{m}$ (MERCK KGaA, Germany), amount of CSP in each column: $25 \mathrm{~g}$;

Temperature: $25{ }^{\circ} \mathrm{C}$; recycling dead volume: $20 \mathrm{~mL}$,

SMB flowrates: recycling: $32.53 \mathrm{~mL} / \mathrm{min}$; feed: $2.88 \mathrm{~mL} / \mathrm{min}$; eluent: $10.73 \mathrm{~mL} / \mathrm{min}$; extract: $9.92 \mathrm{~mL} / \mathrm{min}$, raffinate: $3.69 \mathrm{~mL} / \mathrm{min}$; period: $13.46 \mathrm{~min}$.

The enantioselective crystallization behavior of this compound in the eluent has been studied, starting from enriched enantiomer solutions. The point of maximal solubility showed to be the racemic mixture, which is the most favourable case, since all the enantiomeric excess can be recovered as pure enantiomer by crystallization. In fact, this type of chiral compounds is called conglomerate: the solids are composed of separate crystals of both enantiomers.

A simulation software has been used to optimize the complete process (SMB + crystallization), allowing to get a very pure (+) enantiomer, with the best productivity. Figure 9 clearly shows two separate optima:

- the minimal eluent consumption (14\% saving) is obtained for a feed flow rate equal to 2-fold the feed flow rate of the optimized SMB. The extract optical purity is only 
$83 \%$, but the overall theoretical productivity is increased by $60 \%$ compared to the single SMB process.

- the maximal productivity is obtained for a feed flow rate equal to about 3 -fold the nominal feed flow rate. In these conditions, the extract optical purity drops to $70 \%$, but the overall productivity is increased by $70 \%$ compared to the single SMB process.

\section{GMP aspects}

As this technique is expected to be used for the pharmaceutical industry, the compliance with quality norms is a prerequisite for success; the following non exhaustive list highlights some important points:

- The optimisation of the process should take into account the actual availability of the stationary phase and its batch-to-batch reproducibility. For a preparative chromatography process, this implies the development of a testing method allowing one to precisely determine the loading (capacity) of the stationary phase, more critical than simple retention times of test solutes.

- The definition of the chromatographic process limits is a key point. As discussed in 6.1, in some cases, the chromatographic system (SMB + evaporators) can be defined as a single box, allowing one to get concentrated products. In that case, there is no need of intermediate controls. Moreover, there is no need of investing in buffer tanks.

- Another important parameter is the eluent composition: binary mixtures (and obviously pure solvents) should be preferred to complex mixtures, since new systems perform an on-line analysis of the composition of binary eluents. They allow the automatic eluent recycling, with a reduced number of controls. These are limited to the analysis of possible traces of feed components periodically.

- The maximum performance of the process should be known, and a reasonable safety margin has to be applied to the productivity in order to allow the process to be "robust", that is to say to achieve reproducible purities, yields and concentration factors. This implies the achievement of "worse cases", which can be performed on the industrial unit (in that case it is too late!) and preferably on a pilot plant unit. This work can be prepared and partly achieved using computer simulations, which allows one to save much time.

\section{A new and powerful technique: SMB with supercritical $\mathrm{CO}_{2}$ and eluent strength modulation}

Due to environmental and safety regulations becoming more and more stringent, an increasing number of organic solvents are now "material non grata" in the last steps of manufacture of pharmaceutical compounds. Among remaining acceptable solvents, $\mathrm{CO}_{2}$ is certainly the ideal one:

- it is nearly non toxic (everyone breathes several $\mathrm{kg}$ of $\mathrm{CO}_{2}$ per year at least),

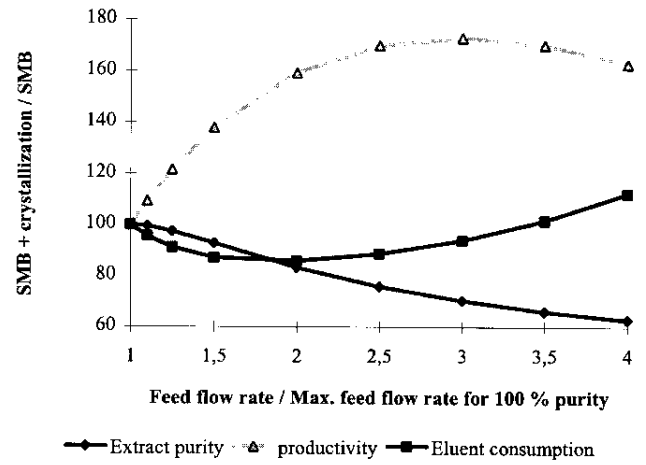

Figure 9. Influence of a coupling between a SMB and crystallisation on the overall process performance.

- it is cheap,

- its polarity (and thus eluent strength in chromatography) can be simply modulated with the pressure.

Supercritical fluid chromatography (SFC) has been developed, and showed interesting performances, for instance for fatty acids or enantiomer separations.

- A new SMB process using $\mathrm{CO}_{2}$ as the eluent (SF-SMB) has been proposed $[12,41]$.

The SMB chromatographic process can take great advantage of the $\mathrm{CO}_{2}$ pressure modulation:

Referring to the function of the four zones in the SMB (see Sect. 2 above).

- In zone I, the more retained compound has to be desorbed from the stationary phase. In a liquid SMB, this implies a high eluent flow rate. In the SF-SMB, the $\mathrm{CO}_{2}$ pressure can be increased in zone I. Therefore, the solubility of the more retained compound in the $\mathrm{CO}_{2}$ can be drastically enhanced, and as a consequence, the desorption from the stationary phase is faster, or requires a lower $\mathrm{CO}_{2}$ flow rate.

- In zone IV, the less retained compound has to be adsorbed on the stationary phase. By reducing the $\mathrm{CO}_{2}$ pressure, the solubility of this compound in the $\mathrm{CO}_{2}$ is drastically decreased. Therefore, a much shorter stationary phase length (for instance one column instead of two in a classical SMB) can be sufficient.

- Moreover, the natural pressure gradient in the SMB created by the high speed $\mathrm{CO}_{2}$ flow in the columns packed with small particles tends to enhance these effects.

These features contribute to reduce the stationary phase inventory needed for a given production, therefore the size of the equipment and the separation cost.

Consequently, the interest of SF-SMB is not only linked to the replacement of an organic solvent by carbon dioxyde, but also to the possibility to run a spatial gradient inside the system, as clearly shown in a recent theoretical paper (Mazzotti et al., 1997). 


\section{Conclusion}

Since its introduction in the fine chemical and pharmaceutical industries, the SMB technology has gone through a number of developments. For, this technology is now very different from the systems initially designed for petrochemical applications. We can now speak about high performance $\mathrm{SMB}$, in comparison to HPLC with respect to classical liquid chromatography. These new SMBs whould now be designed as a part of a complete unit operation, including concentration of the product, recycling of the eluent, and often a further crystallization (in the case of most enantiomers) leading to the isolation of a pure material, with a robust global process.

Beside the improvements of liquid phase SMB, this counter-current process has been successfully developed with supercritical fluids as eluents. Mainly suited to the separation of certain classes of compounds such as lipids, this new technique, which takes advantage of physical modulations allowed by a non toxic compressible fluid, opens the way to cleaner and safer purification processes.

The future trends in the development of SMB are certainly linked to advanced and "intelligent" process control systems, coupled with interactive modeling softwares. The basic tools have now been developed, but some years will be necessary before considering the SMB as a simple black box.

\section{References}

1. Balannec, B.; Hotier, G. "From batch to countercurrent chromatography", in Preparative and Production Scale Chromatography, Ganetsos G. and Barker P. E. Eds., Marcel Dekker, New York, 1993.

2. Bailly, M.; Nicoud, R. M. The Simulated Moving Bed: A powerful process for purification. Proceedings Balannec B. and Hotier G., "From batch to countercurrent chromatography", in Preparative and Production Scale Chromatography, Ganetsos G. and Barker P. E. Eds., Marcel Dekker, New York, 1993.

3. Barker, P. E.; Critcher, Chem. Eng. Sci. 1960, 13, 82.

4. Blehaut, J.; Charton, F.; Nicoud, R. M. LC-GC Intl. 1996, 9(4), 228-238.

5. Blezer, H. J.; De Rosset, A. J. Die Starke 1977, 29, 393.

6. Broughton, D. B. US Patent 1961, 2, 985-589.

7. Cavoy, E.; Deltent, M. F.; Lehoucq, S.; Miggiano, D. J. Chrom. 1997, 769, 49-57.

8. Charton, F.; Nicoud, R. M. J. Chrom. A 1995, 702, 97-112 of "Biotechnology of Blood Proteins", Colloque INSERM / John Libbey Eurotext Ltd Vol. 227, pp 13-18.

9. Ching, C. B.; Ruthven, D. M. Chem. Eng. Sci. 1985, 40, 877.

10. Ching, C. B.; Ruthven, D. M.; Hidajat, K. Chem. Eng. Sci. 1985, 40, 1411.

11. Ching, C. B.; Lim, B. G.; Lee, E. J. D.; Ng, S. C. J. Chrom. 1993, 634, 215-219.

12. Clavier, J. Y.; Nicoud, R. M.; Perrut, M. In: Rudolph von Rohr Ph., Trepp Ch. Eds., High Pressure Chemical Engineering, Elsevier, London, 1996.

13. Collet, A. "Chiral separations by HPLC: applications to pharamaceutical compounds.”, Chap. 4: Optical resolution by crystallisation methods, Krstulovic A. M. Ed., 1989; pp 81-104.

14. Ernst, U. P.; Hsu, J. T. Ind. Eng. Chem. Res. 1989, 28, 1211.
15. Francotte, E. Proceedings of Chiral Europe 96, Strabsbourg 14-15 October 1996, Published by Spring Innovations Ltd, Stocport, England, 1996.

16. Fuchs, G.; Nicoud, R. M.; Bailly, M. in Proceedings of the 9th Symposium on Preparative and Industrial Chromatography “Prep 92", INPL, Nancy, France, 1992; pp 205-220.

17. Ganetsos, G.; Barker, P. E. "Semi Continuous Chromatographic Refiners", in Preparative and Production Scale Chromatography, Ganetsos G. and Barker P.E. Eds., Marcel Dekker, New York, 1993.

18. Gottschlich, N.; Kasche, V. J. Chrom. A 1997, 201-206.

19. Guerrier, L. personnal communication.

20. Guest, D. W. Evaluation of simulated moving bed chromatography for pharmaceutical process development, $J$. Chromatography A 1997, 760, 159-162.

21. Hotier, G. The ELUXYL process: from the idea to the largest SMB unit in the world. Published during a meeting organized by NOVASEP on May, $15^{\text {th }}, 1997$.

22. Hotier, G.; Nicoud, R. M. US Patent 5, 578, 216.

23. Hotier, G.; Cohen, C.; Couenne, N.; Nicoud, R. M. US Patent $5,578,216$.

24. Hashimoto, K.; Adachi, S.; Shirai, Y.; Moritshita, M. "Operation and design of Simulated Moving Bed adsorbers", in Preparative and Production scale Chromatography, Ganetsos G. and Barker P.E. Eds., Marcel Dekker, 1992.

25. Hashimoto, K.; Adashi, S.; Noujima, H.; Maruyama, H. J. Chem. Eng. Jpn. 1983, 16, 400.

26. Hashimoto, K.; Adashi, S.; Shirai, S. Agric. Biol. Chem. 1988, 52, 2161.

27. Houwing, J. et al. Delft University, The Netherlands, Proceedings of the First European Symposium on Biochemical Engineering Science, ISBN 1872327109, Dublin, September, 1996.

28. Huang, S. Y.; Lin, C. K.; Chang, W. H.; Lee, W. S. Chem. Eng. Commun. 1986, 456, 291.

29. Kampen, W. H. European Patent Application, 90307701.4.

30. Kinkel, J. N. Proceedings of Chiral Europe 95, 28-29 Sept. 1995, London, Published by Spring innovation Ltd, Cheshire, SK7 1BA, England, 1995.

31. Kishihara, S. et al. J. Chem. Eng. Jpn. 1989, 22(4), 434.

32. Küsters, E. Proceedings of Chiral Europe 95, Published by Spring Innovation Ltd., Stockport, England, 1995.

33. Maki, H.; Fukuda, H.; Morikawa, H. J. Ferment. Technol. 1987, 65, 61 .

34. Maki, H. Separation of Gluthatione and glutamic acid using a SMB adsorber systemfin Preparative and Production scale Chromatography, Ganetsos, G. and Barker, P. E. Eds., Marcel Dekker, 1992.

35. Mazzotti, M.; Pedeferri, M. P.; Morbidelli, M. Proceedings of Chiral Europe 96, Strabsbourg 14-15 October 1996, Published by Spring Innovations Ltd, Stocport, England, 1996.

36. Mazzotti, M.; Storti, G.; Morbidelli, M. J. Chrom. A 1997, 769, 3-24.

37. Nagamatsu, S.; Makino, S. poster presented during the International Symposium on Chiral Discrimination, Nagoya, 1997.

38. Negawa, M.; Shoji, F. J. Chrom. 1992, 590, 113-117.

39. Nagamatsu, Proceedings of Chiral Europe 96, Strabsbourg 1415 October 1996, Published by Spring Innovations Ltd, Stocport, England, 1996.

40. Nicoud, R. M. The simulated moving bed: a powerful chromatographic process, LC-GC INTL 1992, 5(5), 43-47.

41. Nicoud, R. M.; Perrut, M. French Patent 9205 304, 1992.

42. Nicoud, R. M.; Bailly, M. Choice and optimization of operating modes in industrial chromatography. Proceedings of "PREP'92", Nancy (France), 6-8 April 1992, ISBN 2-905267 - 18 - 6; pp 205-220. 
43. Nicoud, R. M. Large-scale fractionation of optical isomers by simulated moving bed chromatography. Proceedings of Chiral Europe'96, Strasbourg (France); pp 117-119.

44. Nicoud, R. M.; Fuchs, G.; Adam, P.; Bailly, M.; Küsters, E.; Antia, F.D; Reuille, R.; Schmid, E. Chirality 1993, 5, 267.

45. Nicoud, R. M. LC-GC Int. 1993, 6(10).

46. Nicoud, R. M.; Bailly, M.; Kinkel, J.N.; Devant, R.; Hampe, T.; Küsters, E. in Nicoud R. M. Ed., Simulated Moving Bed: Basics and applications, INPL, Nancy, France, 1993; pp 6588.

47. Nicoud, R. M. Proceedings of the Chiral Europe 96, Strasburg, 14-15 October 1996, Spring innovation Ltd Publisher, Cheshire, SK7 1BA, 1996.
48. Nicoud, R. M. Recovery of Biological Products VIII, ACS, 2025 October 1996, Tucson, Arizona.

49. Pais, L. S.; Loureiro, J. M.; Rodrigues, A. E. Chem. Eng. Sci. 1997, 52, 245.

50. Pronova: European patent application, 697034, 1996.

51. Strube et al. J. Chrom. A 1997, 769, 81-92.

52. Szpepy et al. J. Chrom. 1975, 108, 285-297.

53. Tondeur, D.; Bailly, M. in Simulated Moving Bed: Basics and applications, Nicoud R.M. Ed., INPL, Nancy, France, 1993, pp 95-117.

54. Van Walsem, H. J.; Thompson, M. C. (AECI Bioproducts, Durban, South Africa), First European Symposium on Biochemical Engineering Science, ISBN 1872327109, Dublin, September 1996. 